\title{
Article \\ Differential Effects of Various Soy Isoflavone Extracts on Bacterial Growth and Human Fibroblast Viability
}

\author{
Agata Rzeszótko ${ }^{1,2}$, Aleksandra Blendowska ${ }^{1}$, Grzegorz Węgrzyn ${ }^{1}$ and Karolina Pierzynowska 1,* \\ 1 Department of Molecular Biology, University of Gdańsk, Wita Stwosza 59, 80-308 Gdańsk, Poland; \\ agata.rz1@wp.pl (A.R.); aleksandra.blendowska@onet.pl (A.B.); grzegorz.wegrzyn@biol.ug.edu.pl (G.W.) \\ 2 Wacław Sierpiński High School, Kopernika 34, 81-424 Gdynia, Poland \\ * Correspondence: karolina.pierzynowska@biol.ug.edu.pl; Tel.: +48-58-523-6036
}

\begin{abstract}
Flavonoids, compounds present in many dietary supplements, affect growth of different bacterial species when tested as purified or synthetic substances. Here, we asked if soy isoflavone extracts, commonly used in many products sold as anti-menopausal dietary supplements, influence bacterial growth similarly to synthetic isoflavone, genistein. Four commercially available products were tested in amounts corresponding to genistein concentrations causing inhibition of growth of Vibrio harveyi (a model bacterium sensitive to this isoflavone) and Escherichia coli (a model bacterium resistant to genistein). Differential effects of various extracts on $V$. harveyi and $E$. coli growth, from stimulation, through no changes, to inhibition, were observed. Moreover, contrary to genistein, tested extracts caused a decrease (to different extends) in viability of human dermal fibroblasts. These results indicate that effects of various soy isoflavone extracts on bacterial growth and viability of human cells are different, despite similar declared composition of the commercially available products.
\end{abstract}

Keywords: genistein; soy isoflavone extracts; anti-menopausal dietary supplements; bacterial growth; viability of human cells

\section{Introduction}

Flavonoids are polyphenolic compounds present in many food products, including vegetables, fruits, tea and others [1]. They are known as molecules of various biological activities [2, 3]. Among these activities, some have been recognized as beneficial for human health, particularly: antioxidative properties, free radical scavenging capacity, coronary heart disease prevention, hepatoprotective, anti-inflammatory, and anticancer functions, as well as antiviral and antimicrobial actions [4]. Some studies indicated that flavonoids, especially isoflavones, can be also considered as drugs for genetic diseases $[5,6]$.

It was demonstrated previously that certain flavonoids have antibacterial activities which may result from inhibition of synthesis of macromolecules [7]. Subsequent studies confirmed this discovery and extended our knowledge in the field (summarized in [8, 9]). In fact, recent reports indicated that flavonoids can significantly influence human intestinal microbiota by inhibiting growth of certain bacterial species [8]. This is also true for dietary flavonoids and those present in food supplements or nutraceuticals [10]. 
One of the most popular groups of dietary supplements and nutraceuticals are soy isoflavones [11]. Isoflavone-rich soy extracts (in which genistein is a predominant flavonoid) are commonly used products recommended against menopausal symptoms [12]. On the other hand, isoflavones are one of the strongest antimicrobial agents among flavonoids, with genistein giving the most pronounced results $[7,13]$. Therefore, the aim of this work was to test effects of commercially available dietary supplements/nutraceuticals containing soy isoflavone extracts (rather than purified isoflavones or their mixtures with precisely defined content) on model bacterial species. We asked the question how these commonly available dietary supplements and nutraceuticals might influence growth of bacteria. As models, the most sensitive to isoflavones - Vibrio harveyi, and the most resistant to these compounds - Escherichia coli, bacterial species (as determined previously [13]), were chosen. Moreover, effects of these extracts on viability of human cells (dermal fibroblasts) were tested. These studies were also substantiated by the fact that previous reports indicated that various commercially available soy extracts differ considerably in actual amounts of isoflavones relative to those declared by manufacturers [14-16]. Therefore, we assumed that testing biological activities of these products is of particular interest. Our results indicated differential effects of various soy isoflavone extracts on bacterial growth and human fibroblast viability, highlighting the problem of different quality of certain dietary supplements and nutraceuticals sold over-the-counter in vast majority of, if not all, countries.

\section{Materials and Methods}

\subsection{Bacterial strains and growth conditions}

Laboratory strains $V$. harveyi BB7 [17] and E. coli MG1655 [18] were used. Bacteria were cultured in nutrient media, either BOSS [19] (for $V$. harveyi cultivation) or LB [20] (for E. coli cultivation), at either $30^{\circ} \mathrm{C}\left(V\right.$. harveyi) or $37^{\circ} \mathrm{C}$ (E. coli) in shaking flasks.

\subsection{Cell line and cell cultures}

The cell line of human dermal fibroblasts - adult (the HDFa line) was employed. Cells were maintained in the DMEM medium containing $10 \%$ fetal bovine serum and the penicillinstreptomycin mixture. Cells were cultured at $37^{\circ} \mathrm{C}$ in a humidified atmosphere with $5 \% \mathrm{CO}_{2}$.

\subsection{Soy isoflavone extracts and synthetic genistein}

Four commercially available products, registered as either medicines/nutraceuticals or dietary supplements, which should contain considerable amounts of soy isoflavones, as declared by the manufacturers, were used. These products, referred to as extracts no. 1, 2, 3 and 4 in this report, were purchased commercially in Poland. The compositions of these extracts, according to information provided by manufacturers, are shown in Table 1 . Synthetic genistein (manufactured as described previously [21]) was purchased from Pharmaceutical Research Institute in Warsaw (Poland). 
Table 1. Compositions of tested extracts

\begin{tabular}{|c|c|}
\hline Extract no. & Composition (amount per tablet) \\
\hline Extract 1 & $\begin{array}{l}\text { Soy concentrate }(125 \mathrm{mg}) \text { including soy isoflavones }(50 \mathrm{mg}) \text {, calcium } \\
(500 \mathrm{mg}) \text {, vit. D3 }(5 \mu \mathrm{g}) \text {, thiamine }(1.4 \mathrm{mg}) \text {, riboflavin }(1.6 \mathrm{mg}) \text {, vit. B6 } \\
(2 \mathrm{mg}) \text {, vit. B12 }(3 \mu \mathrm{g}) \text {, biotin }(150 \mu \mathrm{g}) \text {, folic acid }(150 \mu \mathrm{g})\end{array}$ \\
\hline Extract 2 & 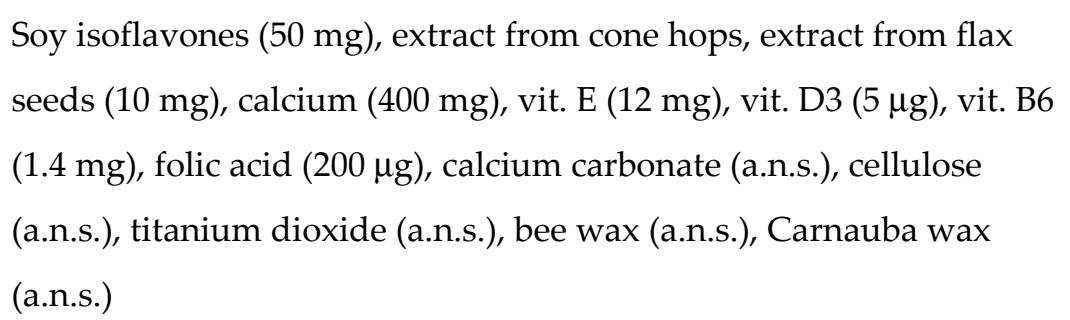 \\
\hline Extract 3 & $\begin{array}{l}\text { Soy concentrate }(350 \mathrm{mg} \text { ) including soy isoflavones ( } 35 \mathrm{mg}) \text {, gelatin } \\
\text { (a.n.s.), magnesium stearate (a.n.s.), titanium dioxide (a.n.s.) }\end{array}$ \\
\hline Extract 4 & $\begin{array}{l}\text { Soy concentrate }(100 \mathrm{mg}) \text { including soy isoflavones }(26 \mathrm{mg}) \text {, } \\
\text { microcrystal cellulose (a.n.s.), magnesium stearate (a.n.s.), talc } \\
\text { (a.n.s.), glycerol (a.n.s.) }\end{array}$ \\
\hline
\end{tabular}

Compositions are as provided by manufacturers; a.n.s., amount not specified by manufacturer

\subsection{Monitoring of bacterial growth}

Bacteria were cultured overnight under conditions described above. Following dilution of the culture with fresh medium, at the v/v ratio 1:100, bacteria were cultured under the same conditions, and $\mathrm{A}_{595}$ was measured every $15 \mathrm{~min}$. The extracts were purchased in the form of tablets, which were crushed and dissolved in DMSO. Such extracts were added to the bacterial cultures at A595 = 0.1 to final concentrations corresponding to 30,60 and $100 \mu \mathrm{M}$ genistein (included in each extract). In control experiments, either DMSO (negative control) or genistein (positive control) was added. Growth curves were analyzed, and bacterial generation times were calculated on the basis of A595 values at the exponential phase of bacterial culture growth.

\subsection{MTT cell viability assay}

$4 \times 10^{3}$ HDFa cells were passaged in each well of 96-well plate, and allowed to attached overnight. Cells were then treated with DMSO (negative control), or 30, 60 or $100 \mu \mathrm{M}$ genistein (positive control), or extracts (at final concentrations corresponding to 30, 60 or $100 \mu \mathrm{M}$ genistein, included in each extract) at $37^{\circ} \mathrm{C}$. After 24 or $48 \mathrm{~h}$ incubation, $25 \mu \mathrm{l}$ of MTT solution $(4 \mathrm{mg} / \mathrm{ml}) \mathrm{was}$ added to each well. Following $3 \mathrm{~h}$ incubation at $37{ }^{\circ} \mathrm{C}$, formazan crystals, formed in living cells, were dissolved in $100 \mu \mathrm{l}$ of DMSO. Absorbance was measured at $570 \mathrm{~nm}$ and $620 \mathrm{~nm}$ (reference wavelength) in a Victor $^{3}$ microplate reader. 


\section{Results and Discussion}

It was reported previously that determination of growth rate, particularly generation time, in a liquid culture can be considered as an optimal method for estimation of effects of flavonoids on bacteria [13]. This is because methods based on diffusion are problematic due to low rate of diffusion of flavonoids, and other factors (like inoculum size, disk size, incubation period) may influence the results [22]. Therefore, to determine if tested soy isoflavone extracts influence growth of two bacterial species, $V$. harveyi (previously demonstrated to be sensitive to genistein $[7,13]$ ), and E. coli (previously demonstrated to be resistant to genistein $[7,13]$ ), we monitored growth of bacterial liquid cultures and calculated generation times in the presence and absence of isoflavone(s).

Representative growth curves are presented in Fig. 1 (for V. harveyi) and Fig. 2 (for E. coli), and calculated generation times are shown in Table 2 (for $V$. harveyi) and Table 3 (for E. coli). Generation times were calculated for two time periods, first, from the addition of the tested compound or extract through $30 \mathrm{~min}$ (i.e. $0-30 \mathrm{~min}$, where 0 is the time of the addition), and second, between 60 and 120 min after the addition (i.e. $60-120 \mathrm{~min}$ ). As expected, genistein impaired growth of $V$. harveyi in both time periods, while it had no significant effect on E. coli. However, differential effects were observed for various soy isoflavone extracts. Extract 1 stimulated $V$. harveyi growth shortly $(0-30 \mathrm{~min})$ after its addition to the culture, while strongly inhibiting the growth later on. Similar, though less pronounced, effects were observed for extract 3. On the other hand, extract 2 caused only some stimulation of $V$. harveyi growth shortly after its addition to the culture, and had no significant effect in the $60-120$ min time interval. Extract 4 revealed the weakest effect on $V$. harveyi growth, as the only considerable change in growth rate was noted only at the highest tested concentration between 60 and $120 \mathrm{~min}$ after culture supplementation.

Although genistein did not influence growth of E. coli, extracts 1 and 2 caused a significant shortening of the generation time immediately after their addition to the culture. Moreover, addition of extract 3 at the highest concentration resulted in a longer generation time of the E. coli culture in the time interval $60-120 \mathrm{~min}$.

These results indicated that despite using the same concentrations of soy isoflavones (among which genistein is highly predominated [23]) present in various commercially available products, as declared by extract manufacturers, their effects on bacterial growth were different. These differences might arise from either discrepancies between declared (by manufacturers) and actual amounts of isoflavones in tablets (the phenomenon reported previously for other extracts [16]) or activities of other compounds (either identified molecules or unidentified substances from extracts or both) present in the products (see Table 1). Irrespective of the cause of this phenomenon, differential effects of tested extracts on bacterial growth are evident. This might be especially important in the light of recent studies which demonstrated that flavonoids can significantly influence human gut microbiome $[8,10]$.

Other differential biological effects of various soy isoflavone extracts were reported previously, when synthesis of glycosaminoglycans was tested in human fibroblasts [16]. Therefore, we have also tested effects of investigated extracts on viability of human cells (the HDFa cell line). By using the MTT test, we have estimated the fraction of viable cells after different times of treatment with tested extracts at different concentrations. 

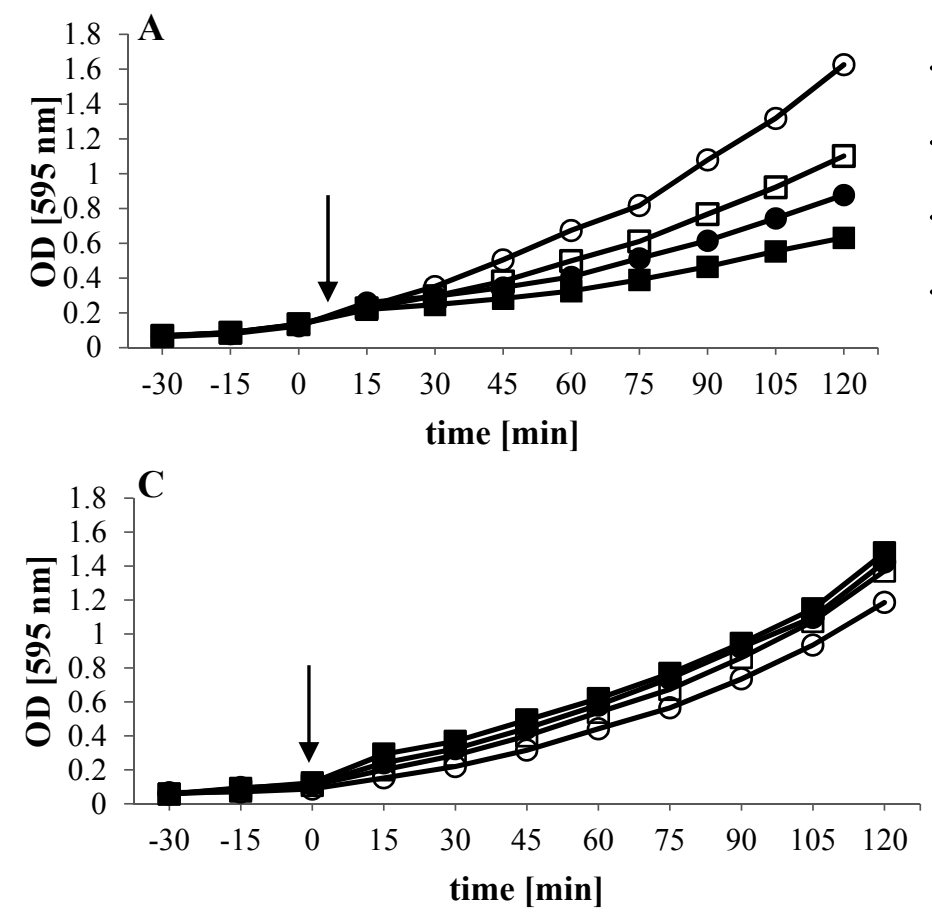

$\multimap$ DMSO

$\square-30 \mu \mathrm{M}$ extract 2

$\longrightarrow 60 \mu \mathrm{M}$ extract 2

$\rightarrow-100 \mu \mathrm{M}$ extract 2

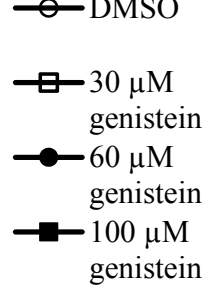

B

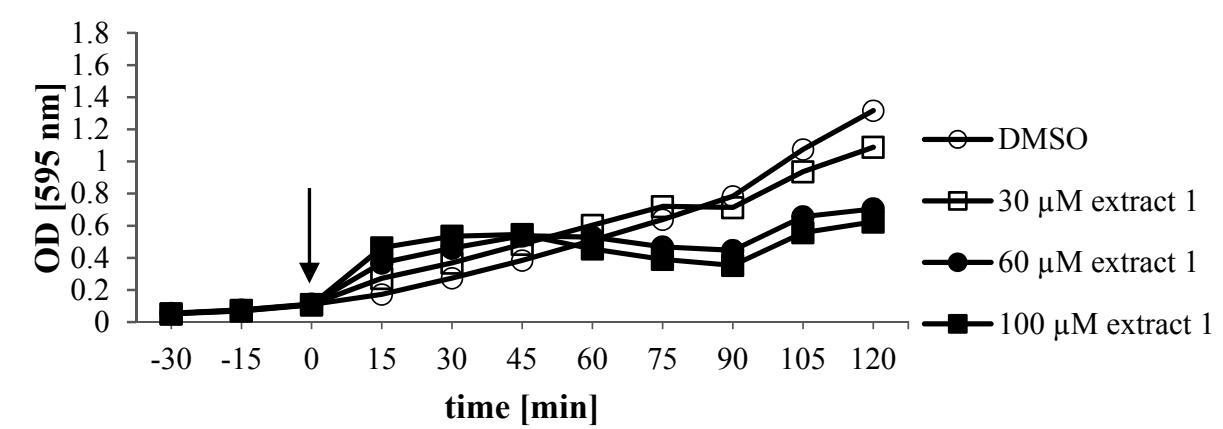

D
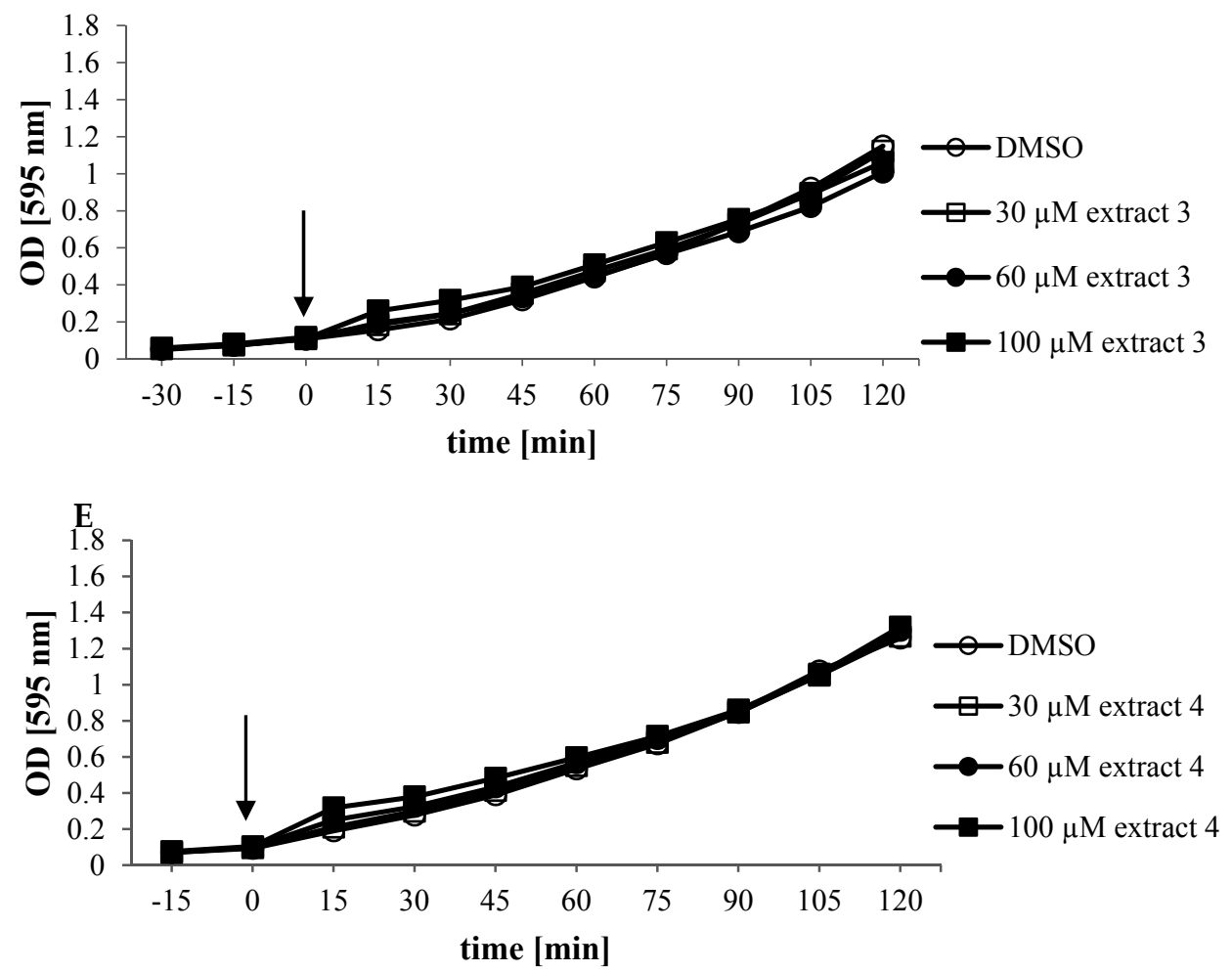

Figure 1. Effects of genistein and different extracts on $V$. harveyi BB7 growth. Bacteria were cultured in the BOSS medium at $30^{\circ} \mathrm{C}$, and different compounds were added at time 0 to indicated concentrations. Representative growth curves are shown. 

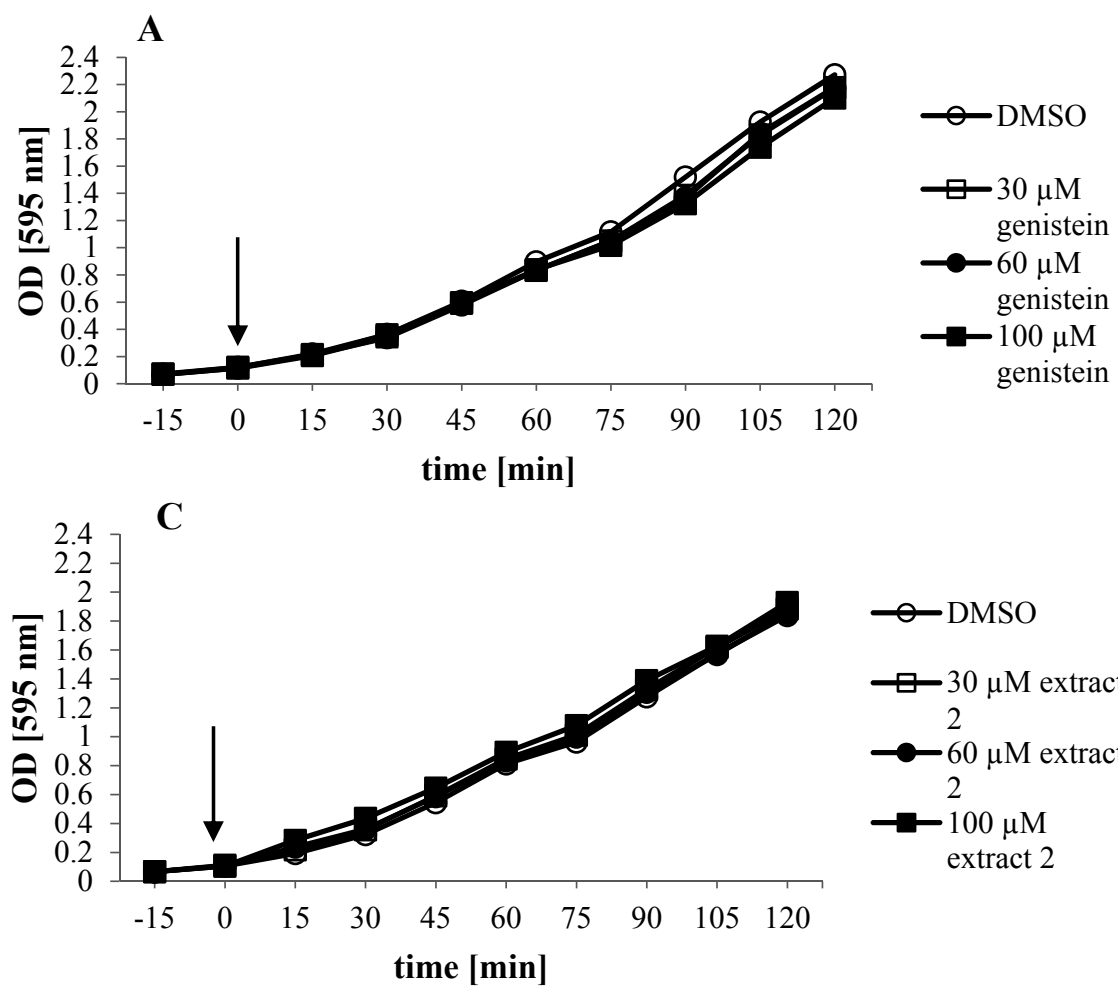

-DMSO

$\square-30 \mu \mathrm{M}$ extract

$\stackrel{2}{-60 \mu \mathrm{M} \text { extract }}$

$-200 \mu \mathrm{M}$

extract 2

time [min]

Figure 2. Effects of genistein and different extracts on E. coli MG1655 growth. Bacteria were cultured in the $\mathrm{LB}$ medium at $37^{\circ} \mathrm{C}$, and different compounds were added at time 0 to indicated concentrations. Representative growth curves are shown.
B

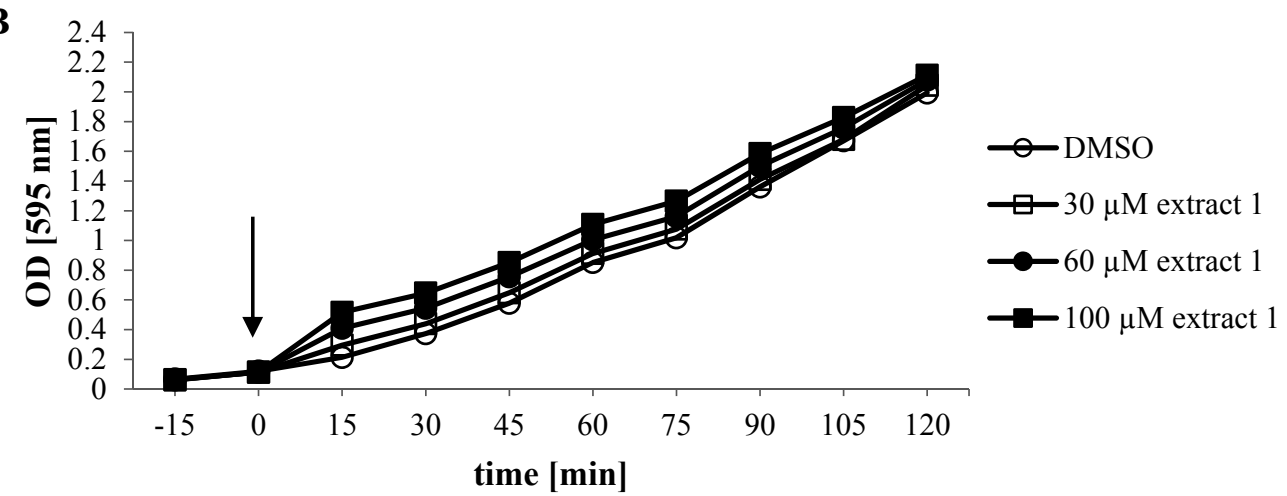

D

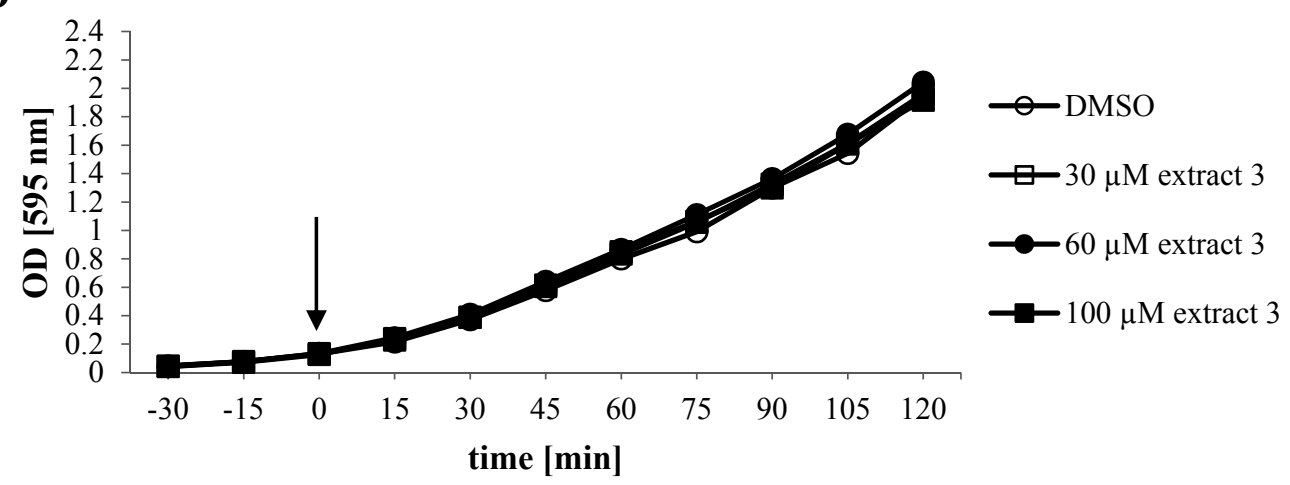

E

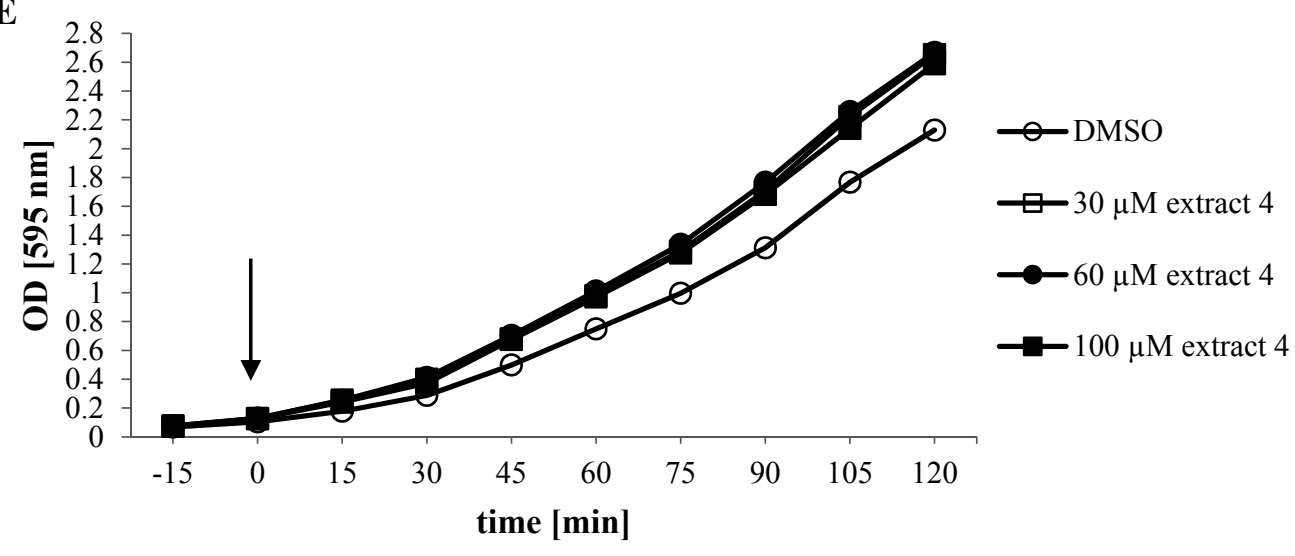


Table 2. Generation times of $V$. harveyi cultures treated with different compounds

\begin{tabular}{|c|c|c|c|c|c|c|}
\hline Sample & $\begin{array}{l}\text { Generation } \\
\text { time ( } \mathrm{min}) \\
{[0-30 \mathrm{~min}]}\end{array}$ & $\begin{array}{l}p \text { value: } \\
\text { sample vs. } \\
\text { DMSO }\end{array}$ & $\begin{array}{l}p \text { value: } \\
\text { sample vs. } \\
\text { genistein }\end{array}$ & $\begin{array}{l}\text { Generation } \\
\text { time (min) } \\
{[60-120 \mathrm{~min}]}\end{array}$ & $\begin{array}{l}p \text { value: } \\
\text { sample vs. } \\
\text { DMSO }\end{array}$ & $\begin{array}{l}p \text { value: } \\
\text { sample vs. } \\
\text { genistein }\end{array}$ \\
\hline \multicolumn{7}{|l|}{ Genistein } \\
\hline $\begin{array}{l}0 \mu \mathrm{M} \\
(\mathrm{DMSO})\end{array}$ & $24 \pm 2$ & N/A & N/A & $42 \pm 3$ & N/A & N/A \\
\hline $30 \mu \mathrm{M}$ & $26 \pm 1$ & 0.0913 & N/A & $50 \pm 3$ & $0.0168^{*}$ & N/A \\
\hline $60 \mu \mathrm{M}$ & $29 \pm 5$ & $0.0451^{*}$ & N/A & $53 \pm 3$ & $0.0054^{*}$ & N/A \\
\hline $100 \mu \mathrm{M}$ & $34 \pm 4$ & $0.0190^{*}$ & $\mathrm{~N} / \mathrm{A}$ & $60 \pm 3$ & $0.0014^{*}$ & N/A \\
\hline \multicolumn{7}{|l|}{ Extract 1} \\
\hline $\begin{array}{l}0 \mu \mathrm{M} \\
(\mathrm{DMSO})\end{array}$ & $24 \pm 1$ & N/A & N/A & $42 \pm 2$ & N/A & N/A \\
\hline $30 \mu \mathrm{M}$ & $18 \pm 1$ & $0.0013^{*}$ & $0.0001^{*}$ & $60 \pm 11$ & $0.0387^{*}$ & 0.1704 \\
\hline $60 \mu \mathrm{M}$ & $15 \pm 0$ & $0.0002^{*}$ & $0.0212^{*}$ & $109 \pm 36$ & $0.0387^{*}$ & 0.0623 \\
\hline $100 \mu \mathrm{M}$ & $13 \pm 1$ & $0.0010^{*}$ & $0.0010^{*}$ & $133 \pm 52$ & $0.0388^{*}$ & 0.0722 \\
\hline \multicolumn{7}{|l|}{ Extract 2} \\
\hline $\begin{array}{l}0 \mu \mathrm{M} \\
(\mathrm{DMSO})\end{array}$ & $22 \pm 0$ & N/A & N/A & $42 \pm 5$ & N/A & N/A \\
\hline $30 \mu \mathrm{M}$ & $21 \pm 2$ & 0.2561 & $0.0420^{*}$ & $45 \pm 6$ & 0.5641 & 0.3980 \\
\hline $60 \quad M$ & $20 \pm 1$ & $0.0022^{*}$ & $0.0112^{*}$ & $47 \pm 1$ & 0.1647 & $0.0530^{*}$ \\
\hline $100 \mathrm{M}$ & $19 \pm 2$ & $0.0249^{*}$ & $0.0004^{*}$ & $48 \pm 5$ & 0.1804 & $0.0295^{*}$ \\
\hline \multicolumn{7}{|l|}{ Extract 3} \\
\hline $\begin{array}{l}0 \quad \mathrm{M} \\
(\mathrm{DMSO})\end{array}$ & $30 \pm 2$ & N/A & N/A & $44 \pm 3$ & N/A & N/A \\
\hline $30 \mu \mathrm{M}$ & $29 \pm 2$ & 03486 & 0.0550 & $49 \pm 3$ & $0.0161^{*}$ & 0.2564 \\
\hline $60 \mu \mathrm{M}$ & $25 \pm 2$ & $0.0224^{*}$ & 0.4316 & $52 \pm 3$ & $0.0026^{*}$ & 1.0000 \\
\hline $100 \mu \mathrm{M}$ & $20 \pm 3$ & $0.0023^{*}$ & $0.0086^{*}$ & $57 \pm 2$ & $0.0002^{*}$ & 0.0798 \\
\hline \multicolumn{7}{|l|}{ Extract 4} \\
\hline $\begin{array}{l}0 \mu \mathrm{M} \\
(\mathrm{DMSO})\end{array}$ & $21 \pm 2$ & N/A & N/A & $46 \pm 3$ & N/A & N/A \\
\hline $30 \mu \mathrm{M}$ & $21 \pm 3$ & 0.8820 & $0.0390^{*}$ & $48 \pm 2$ & 0.4199 & 0.2771 \\
\hline $60 \mu \mathrm{M}$ & $19 \pm 2$ & 0.4216 & 0.0501 & $49 \pm 2$ & 0.2417 & $0.0540^{*}$ \\
\hline $100 \mu \mathrm{M}$ & $17 \pm 2$ & 0.0890 & $0.0028^{*}$ & $52 \pm 1$ & $0.0158^{*}$ & $0.0112^{*}$ \\
\hline
\end{tabular}

Generation times were calculated in two periods: between 0 and 30 min after addition of genistein or extract (or DMSO in control experiments), and between 60 and $120 \mathrm{~min}$ after addition of genistein or extract (or DMSO in control experiments). Results are presented as mean values from at least 3 independent experiments \pm SD. $p$ values were calculated using the $t$-test, statistically significant differences were assumed when $p<0.05$ (values marked with asterisks). N/A, not applicable. 
Table 3. Generation times of E. coli cultures treated with different compounds

\begin{tabular}{|c|c|c|c|c|c|c|}
\hline Sample & $\begin{array}{l}\text { Generation } \\
\text { time (min) } \\
{[0-30 \mathrm{~min}]}\end{array}$ & $\begin{array}{l}p \text { value: } \\
\text { sample vs. } \\
\text { DMSO }\end{array}$ & $\begin{array}{l}p \text { value: } \\
\text { sample vs. } \\
\text { genistein }\end{array}$ & $\begin{array}{l}\text { Generation } \\
\text { time }(\mathrm{min}) \\
{[60-120 \mathrm{~min}]}\end{array}$ & $\begin{array}{l}p \text { value: } \\
\text { sample vs. } \\
\text { DMSO }\end{array}$ & $\begin{array}{l}p \text { value: } \\
\text { sample vs. } \\
\text { genistein }\end{array}$ \\
\hline \multicolumn{7}{|l|}{ Genistein } \\
\hline $\begin{array}{l}0 \mu \mathrm{M} \\
(\mathrm{DMSO})\end{array}$ & $22 \pm 3$ & N/A & N/A & $41 \pm 4$ & N/A & $\mathrm{N} / \mathrm{A}$ \\
\hline $30 \mu \mathrm{M}$ & $21 \pm 4$ & 0.9027 & N/A & $41 \pm 3$ & 0.9087 & N/A \\
\hline $60 \mu \mathrm{M}$ & $19 \pm 2$ & 0.3022 & N/A & $42 \pm 4$ & 0.8228 & N/A \\
\hline $100 \mu \mathrm{M}$ & $20 \pm 3$ & 0.5790 & N/A & $43 \pm 3$ & 0.4406 & N/A \\
\hline \multicolumn{7}{|l|}{ Extract 1} \\
\hline $\begin{array}{l}0 \mu \mathrm{M} \\
(\mathrm{DMSO})\end{array}$ & $19 \pm 1$ & $\mathrm{~N} / \mathrm{A}$ & N/A & $48 \pm 2$ & $\mathrm{~N} / \mathrm{A}$ & $\mathrm{N} / \mathrm{A}$ \\
\hline $30 \mu \mathrm{M}$ & $16 \pm 1$ & $0.0513^{*}$ & $0.0397^{*}$ & $50 \pm 3$ & 0.5636 & $0.0170^{*}$ \\
\hline $60 \mu \mathrm{M}$ & $14 \pm 1$ & $0.0194^{*}$ & $0.0039^{*}$ & $53 \pm 5$ & 0.4026 & $0.0299^{*}$ \\
\hline $100 \mu \mathrm{M}$ & $12 \pm 1$ & $0.0101^{*}$ & $0.0032^{*}$ & $60 \pm 5$ & 0.1390 & $0.0079^{*}$ \\
\hline \multicolumn{7}{|l|}{ Extract 2} \\
\hline $\begin{array}{l}0 \mu \mathrm{M} \\
(\mathrm{DMSO})\end{array}$ & $19 \pm 1$ & $\mathrm{~N} / \mathrm{A}$ & N/A & $44 \pm 11$ & N/A & $\mathrm{N} / \mathrm{A}$ \\
\hline $30 \mu \mathrm{M}$ & $18 \pm 0$ & $0.0161^{*}$ & 0.1469 & $46 \pm 10$ & 0.8078 & 0.3585 \\
\hline $60 \mu \mathrm{M}$ & $17 \pm 1$ & $0.0132^{*}$ & 0.1518 & $47 \pm 10$ & 0.7427 & 0.3739 \\
\hline $100 \mu \mathrm{M}$ & $16 \pm 1$ & $0.0015^{*}$ & $0.0274^{*}$ & $48 \pm 11$ & 0.6676 & 0.4649 \\
\hline \multicolumn{7}{|l|}{ Extract 3} \\
\hline $\begin{array}{l}0 \mu \mathrm{M} \\
(\mathrm{DMSO})\end{array}$ & $20 \pm 0$ & $\mathrm{~N} / \mathrm{A}$ & N/A & $48 \pm 1$ & $\mathrm{~N} / \mathrm{A}$ & $\mathrm{N} / \mathrm{A}$ \\
\hline $30 \mu \mathrm{M}$ & $20 \pm 1$ & 0.3739 & 0.4267 & $51 \pm 1$ & 0.0647 & 0.0071 \\
\hline $60 \mu \mathrm{M}$ & $19 \pm 1$ & 0.1161 & 1.0000 & $50 \pm 1$ & 0.0572 & $0.0117^{*}$ \\
\hline $100 \mu \mathrm{M}$ & $19 \pm 1$ & $0.0161^{*}$ & 0.2920 & $53 \pm 1$ & $0.0061^{*}$ & $0.0078^{*}$ \\
\hline \multicolumn{7}{|l|}{ Extract 4} \\
\hline $\begin{array}{l}0 \mu \mathrm{M} \\
(\mathrm{DMSO})\end{array}$ & $22 \pm 3$ & $\mathrm{~N} / \mathrm{A}$ & N/A & $41 \pm 4$ & N/A & N/A \\
\hline $30 \mu \mathrm{M}$ & $19 \pm 3$ & 0.3508 & 0.4309 & $42 \pm 3$ & 0.8058 & 0.6843 \\
\hline $60 \mu \mathrm{M}$ & $18 \pm 1$ & 0.0898 & 0.1518 & $44 \pm 3$ & 0.3099 & 0.3867 \\
\hline $100 \mu \mathrm{M}$ & $19 \pm 1$ & 0.2635 & 0.5072 & $43 \pm 1$ & 0.3305 & 1.0000 \\
\hline
\end{tabular}

Generation times were calculated in two periods: between 0 and 30 min after addition of genistein or extract (or DMSO in control experiments), and between 60 and $120 \mathrm{~min}$ after addition of genistein or extract (or DMSO in control experiments).

Results are presented as mean values from at least 3 independent experiments \pm SD.

$p$ values were calculated using the $t$-test, statistically significant differences were assumed when $p<0.05$ (values marked with asterisks).

N/A, not applicable. 
In control experiments, according to previously published results [24], we found no significant cytotoxic effects of synthetic genistein (Figs. 3 and 4). However, $24 \mathrm{~h}$ incubation with extracts were enough to decrease viability of human fibroblasts by extract 1 (at all tested concentrations) and extracts 2 and 3 at certain concentrations (Fig. 3). Even more pronounced cytotoxic effects were observed after $48 \mathrm{~h}$ incubation, when viability of human cells was significantly decreased, particularly in the presence of extracts 1 and 2, and to some extend in the presence of extracts 3 and 4 (Fig. 4).

These results indicated again that various soy isoflavone extracts exhibit differential biological activities despite the same declared (by manufacturers) content of isoflavones. This is true for effects on both bacterial and human cells. Although synthetic genistein demonstrated high level of safety both in vitro [24] and in vivo during clinical studies [25], as well as beneficial profile of antimicrobial effects [13], confirmed in this study, some extracts revealed significant effects on E. coli growth, and their cytotoxicity to human fibroblasts was also detected. Since it was demonstrated that different flavonoids can shape unique gut microbiota profile [26], one might assume a potential influence of isoflavone-rich diet supplements or nutraceuticals on human intestinal flora. It is worth reminding that studies from different countries indicated huge variability in compositions of different soy isoflavone extracts. Setchell et al. [14] analyzed 33 phytoestrogen supplements and extracts, derived from different countries (USA, The Netherlands, and UK) and found considerable differences in the isoflavone content from that claimed by the manufacturers; in some products the differences were 5 to 10-fold, and one product contained no detectable amount of isoflavones. The level of impurities was high in most of the products. Chua et al. [15] found that among 13 commercially available extracts (purchased in the Washington State, USA), only 4 contained at least $90 \%$ of the isoflavone content claimed on the label. Moreover, in 2 products, impurities exceeded $40 \%$ of the total mass of the extract. Piotrowska et al. [16] analyzed 7 commercially available soy isoflavone extracts, and determined that amounts of isoflavones were similar to those declared by manufacturers in only 3 of them. Other products contained significantly less isoflavones than claimed on the label, while one contained 200-fold lower level. Considerable contaminations were detected in isoflavone-poor extracts. These facts should be taken into account when the use of soy isoflavone extracts is considered, especially as local concentrations of the compounds included in a tablet can be high in human intestine after oral administration of these nutraceuticals or dietary supplements.

Acknowledgments: The authors thank Krystyna Bogucka for technical assistance. This work was supported by University of Gdańsk (task grant no. 530-L140-D242-17-1A).

Authors' contributions: AR performed experiments with bacterial cultures. AB participated in experiments with human cell cultures. GW participated in planning experiments, analysis of results, and preparation of the manuscript. KP supervised the project, designed experiments, analyzed results and drafted the manuscript.

Conflict of interest: The authors declare no conflict of interest. 

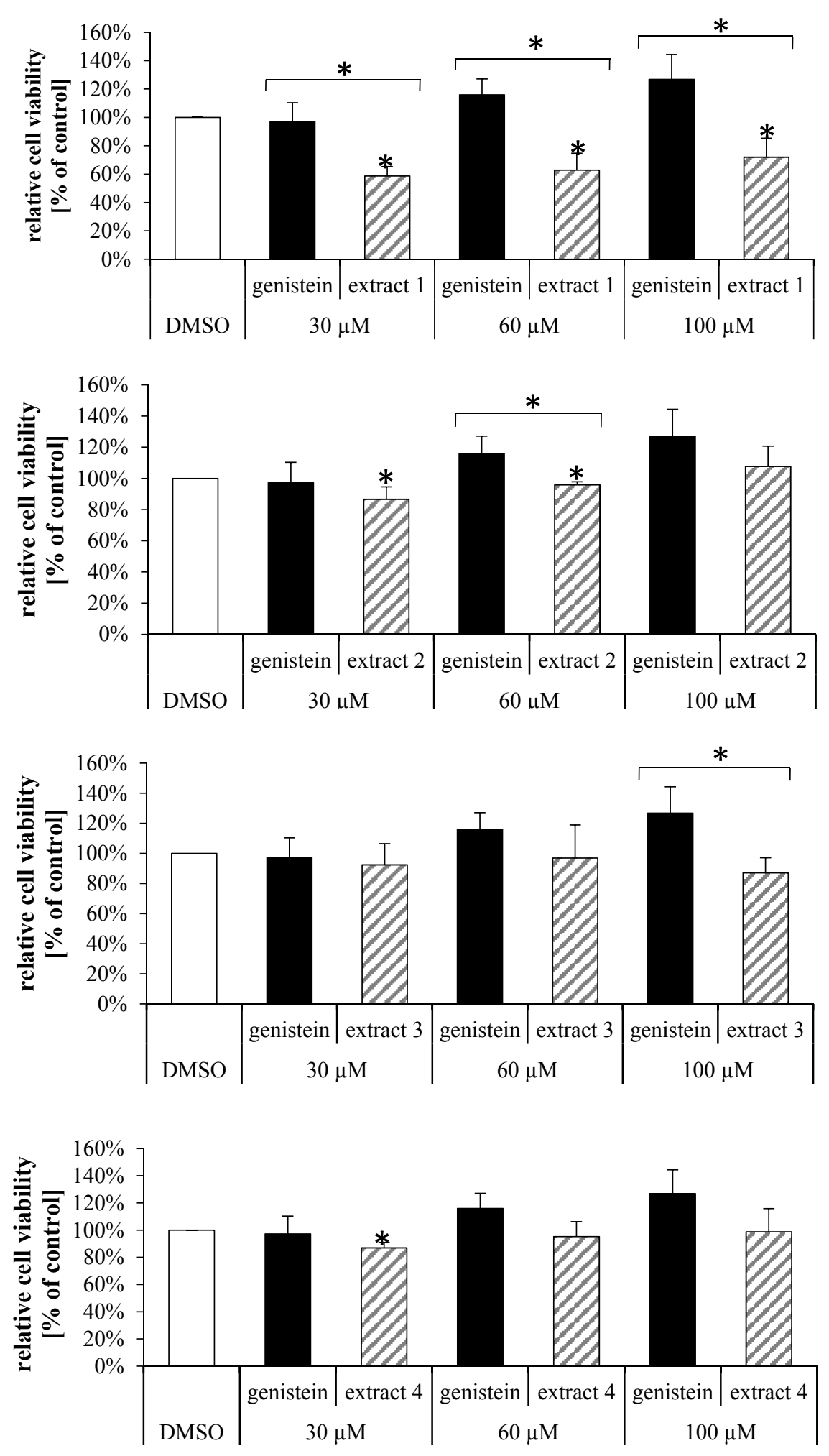

Figure 3. Effects of genistein and different extracts on human cells (the HDFa line) after $24 \mathrm{~h}$ incubation. Either genistein or different extracts were added to the culture medium to indicated final concentrations. DMSO was added in control experiments. The MTT test was performed. Mean values from 3 independent experiments are shown with error bars indicating SD. Statistically significant differences $(p<0.05$ in the $t$-test) are marked with asterisks either above particular columns (differences vs. DMSO control) or above brackets (differences vs. genistein). 

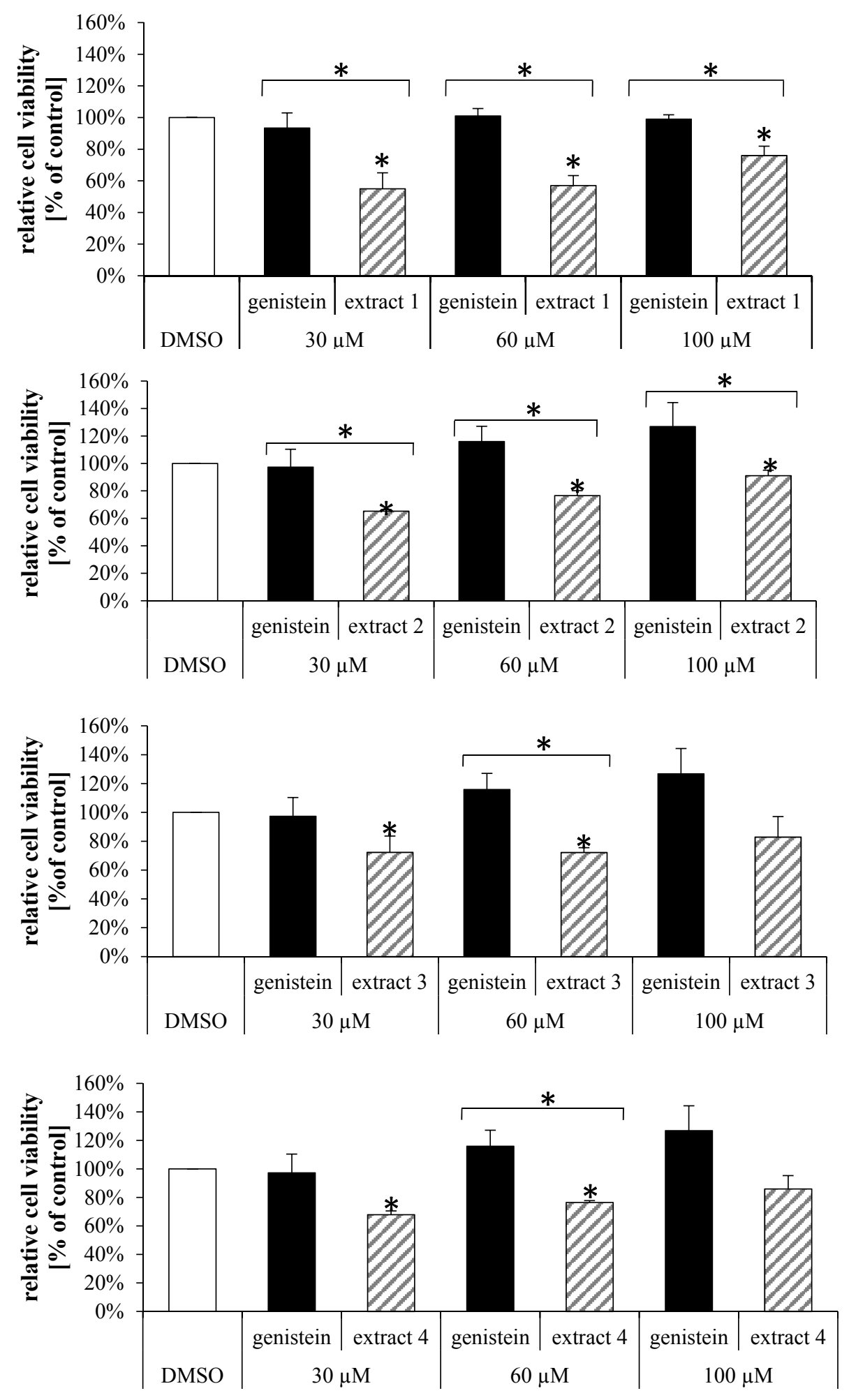

Figure 4. Effects of genistein and different extracts on human cells (the HDFa line) after $48 \mathrm{~h}$ incubation. Either genistein or different extracts were added to the culture medium to indicated final concentrations. DMSO was added in control experiments. The MTT test was performed. Mean values from 3 independent experiments are shown with error bars indicating SD. Statistically significant differences $(p<0.05$ in the $t$-test) are marked with asterisks either above particular columns (differences vs. DMSO control) or above brackets (differences vs. genistein). 


\section{References}

1. Chen, L., Teng, H., Xie, Z., Cao, H., Cheang, W.S., Skalicka-Woniak, K., Georgiev, M.I., Xiao, J. Modifications of dietary flavonoids towards improved bioactivity: an update on structureactivity relationship. Crit Rev Food Sci Nutr, 2017, in press (DOI: 10.1080/10408398.2016.1196334).

2. Mierziak, J., Kostyn, K., Kulma, A. Flavonoids as important molecules of plant interactions with the environment. Molecules 2014, 19, 16240-16265.

3. Mouradov, A., Spangenberg, G. Flavonoids: a metabolic network mediating plants adaptation to their real estate. Front Plant Sci 2014, 5, 620.

4. 4. Kumar, S., Pandey, A.K. Chemistry and biological activities of flavonoids: an overview. Sci World J 2013, 2013, 162750.

5. Wegrzyn, G., Jakóbkiewicz-Banecka, J., Gabig-Cimińska, M., Piotrowska, E., Narajczyk, M., Kloska, A., Malinowska, M., Dziedzic, D., Gołebiewska, I., Moskot, M., Wegrzyn, A. Genistein: a natural isoflavone with a potential for treatment of genetic diseases. Biochem Soc Trans 2010, 38, 695-701.

6. Węgrzyn, A. Gene expression-targeted isoflavone therapy. IUBMB Life 2012, 64, 307-315.

7. Ulanowska, K., Tkaczyk, A., Konopa, G., Węgrzyn, G. Differential antibacterial activity of genistein arising from global inhibition of DNA, RNA and protein synthesis in some bacterial strains. Arch Microbiol 2006, 184, 271-278.

8. Coppo, E., Marchese, A. Antibacterial activity of polyphenols. Curr Pharm Biotechnol 2014, 15, 380-390.

9. Xie, Y., Yang, W., Tang, F., Chen, X., Ren, L. Antibacterial activities of flavonoids: structureactivity relationship and mechanism. Curr Med Chem 2015, 22, 132-149.

10. Marín, L., Miguélez, E.M., Villar, C.J., Lombó, F. Bioavailability of dietary polyphenols and gut microbiota metabolism: antimicrobial properties. Biomed Res Int 2015, 2015, 905215.

11. D'Adamo, C.R., Sahin, A. Soy foods and supplementation: a review of commonly perceived health benefits and risks. Altern Ther Health Med 2014, 20 (Suppl 1), 39-51.

12. Franco, O.H., Chowdhury, R., Troup, J., Voortman, T., Kunutsor, S., Kavousi, M., OliverWilliams, C., Muka, T. Use of plant-based therapies and menopausal symptoms: A systematic review and meta-analysis. JAMA 2016, 315, 2554-2563.

13. Ulanowska, K., Majchrzyk, A., Moskot, M., Jakóbkiewicz-Banecka, J., Węgrzyn, G. Assessment of antibacterial effects of flavonoids by estimation of generation times in liquid bacterial cultures. Biologia 2007, 62, 132-135

14. Setchell, K.D.R., Brown, N.M., Desai, P., Zimmer-Nechemias, L., Wolfe, B.E., Brashear, W.T., Kirschner, A.S., Cassidy, A., Heubi. J.E. Bioavailability of pure isoflavones in healthy humans and analysis of commercial soy isoflavone supplements. J Nutr 2001, 131, S1362-S1375.

15. Chua, R., Anderson, K., Chen, J., Hu, M. Quality, labeling accuracy, and cost comparison of purifi ed soy isofl avonoid products. J Altern Complement Med 2004, 10, 1053-1060.

16. Piotrowska, E., Jakóbkiewicz-Banecka, J., Węgrzyn, G. Different amounts of isoflavones in various commercially available soy extracts in the light of gene expression-targeted isoflavone therapy Phytother Res 2010, 24, S109-S113. 
17. Belas, R., Mileham, A., Cohn, D., Hilmen, M., Simon, M., Silverman, M. Bacterial luminescence: isolation and expression of the luciferase genes from Vibrio harveyi. Science 1982, 218, 791-793.

18. Jensen, K.F. The Escherichia coli "wild types" W3110 and MG1655 have rph frame shift mutation that leads to pyrimidine starvation due to low pyrE expression levels. J Bacteriol 1993, 175, 3401-3407.

19. Klein, G., Żmijewski, M., Krzewska, J., Czeczatka, M., Lipińska, B. Cloning and characterization of the dnaK heat shock operon of the marine bacterium Vibrio harveyi. Mol Gen Genet 1998, 259, 179-189.

20. Sambrook, J., Fritsch, E.F., Maniatis, T. Molecular Cloning: A Laboratory Manual (2nd edn). Cold Spring Harbor Laboratory Press, Cold Spring Harbor, New York, USA, 1989.

21. Grynkiewicz, G., Szeja, W. Synthetic glycosides and glycoconjugates of low molecular weight natural products. Curr Pharm Des 2016, 22, 1592-1627.

22. Cushnie, T.P.T. , Lamb, A.J. Antimicrobial activity of flavonoids. Int J Antimicrob Agents 2005, 26, 343-356.

23. Andres, S., Hansen, U., Niemann, B., Palavinskas, R., Lampen, A. Determination of the isoflavone composition and estrogenic activity of commercial dietary supplements based on soy or red clover. Food Funct 2015, 6, 2017-2025.

24. Kloska, A., Narajczyk, M., Jakóbkiewicz-Banecka, J., Grynkiewicz, G., Szeja, W., GabigCimińska, M., Węgrzyn, G. Synthetic genistein derivatives as modulators of glycosaminoglycan storage. J Transl Med 2012, 10, 153.

25. Kim, K.H., Dodsworth, C., Paras, A., Burton, B.K. High dose genistein aglycone therapy is safe in patients with mucopolysaccharidoses involving the central nervous system. Mol Genet Metab 2013, 109, 382-385.

26. Huang, J., Chen, L., Xue, B., Liu, Q., Ou, S., Wang, Y., Peng, X. Different flavonoids can shape unique gut microbiota profile in vitro. J Food Sci 2016, 81, H2273-H2279.

(C) 2017 by the authors. Licensee Preprints, Basel, Switzerland. This article is an open access article distributed under the terms and conditions of the Creative Commons by Attribution (CC-BY) license (http://creativecommons.org/licenses/by/4.0/). 